\title{
Raptor Collisions with Utility-lines-Now an Important Part of Their Environment and Ours
}

In transmitting electric power from production facilities to their users, utility concerns have erected many hundreds of thousands of kilometres of power- and distribution-lines practically throughout the world. In flight, birds-of-prey (raptors) are usually able to avoid such obstacles; however, when preoccupied or distracted-e.g. when engaged in territorial defence or pursuing prey - the potential for line-strikes increases. This potential is of greatest concern when power-lines are near nest-sites, roosts, or other high-use areas of endangered species.

Although a few actual case-histories of line-strikes by raptors are documented in the literature, efforts to portray utility-line collisions as a significant mortalityfactor have not been convincing. The overall impacts on raptor populations, the specific environmental and behavioural factors which contribute to line-strikes, and appropriate techniques for mitigation, are poorly understood. In view of an ever-increasing demand for electric power and the continuing declines of many raptor populations, a systematic and comprehensive review of the problem is needed.

The US Bureau of Land Management, in cooperation with the Pacific Gas and Electric Company, is assembling all available published and unpublished information concerning raptor/power-line collisions, from which a definitive state-of-the-knowledge report will be pro- duced. Thus, we would very much appreciate the publication of the following call for information in your internationally-influential Journal. As completion of this study is scheduled for the end of the present calendar year (1984), publication of this appeal at the earliest possible date will be necessary for its effective participation in our project:

The US Bureau of Land Management, Sacramento, California, in cooperation with the Pacific Gas and Electric Company, is assembling all available published and unpublished information concerning collisions of raptors with power-lines and other utilitylines. Actual case-histories-no matter how circumstantial or fragmentary - are needed. Please acknowledge that you have such information by writing to Dr Richard R. Olendorff, US Bureau of Land Management, 2800 Cottage Way, Sacramento, California 95825 , USA. A form on which to record your information will then be sent by return mail.

RICHARD R. OlENDORFF, Endangered Species Coordinator United States Bureau of Land Management

California State Office

2800 Cottage Way

Sacramento

California 95825, USA.

\section{Increased Efficiency in Energy-use Could Help to Deal with Global Warming}

According to a new study, increasing the efficiency of energy-use on a world-wide scale could be the most effective way to deal with the global warming that is expected to occur in the next century as carbon dioxide builds up and forms a 'greenhouse' in the atmosphere. Increased efficiency of use, which could cut global energy requirements in half in less than 50 years, is one of several ' $\mathrm{CO}_{2}$-benign' energy strategies suggested in the study that has been prepared for the National Science Foundation (NSF) by engineering and economics specialists at the Massachusetts Institute of Technology (MIT) and Stanford University.

These strategies are based on the potential for greater efficiencies in the use of energy and for accelerating the transition from fossil to non-fossil fuel use. They include nuclear-fission power as well as power from renewable or solar sources such as wind, photovoltaic devices, and the limited use of biomass. Such strategies will be effective only if they are pursued world-wide, and the sooner the better, the report says.

'Most of those strategies, especially increasing energy productivity, are desirable for many other reasonsreducing environmental pollution and helping to reduce international tension both by reducing the pressure on depleting energy resources and by increasing beneficial international collaboration,' according to Dr David J. Rose and Dr Marvin M. Millar, both of MIT, and Dr Carson Agnew of Stanford. Dr Rose was the principal investigator for the study which was undertaken for the NSF's Division of Policy Research and Analysis. 'We conclude, after studying acid rain and other examples, that the time is propitious for enlarging the global discussion on the greenhouse effect,' the report says.

Stringent measures to restrict the use of fossil fuels at this time 'are both unjustified and infeasible', because of the uncertainties that exist in both the timing and consequences of carbon dioxide-induced climate changes 'as well as the possibility of similar impacts due to other so-called greenhouse gases,' the report claims. 'However, given the potential for severe impacts, the possibility that such impacts will have a negative synergism with other environmental stresses occurring at the same time, and the inertia in the energy supply and demand system, it makes sense to develop new strategies for reducing future fossil-fuel carbon emissions, rather than relying solely on research to narrow uncertainties and/or ameliorative measures such as building dikes and developing new strains of 'greenhouse-resistant' crops.'

The greenhouse theory holds that increasing the carbon dioxide levels in the atmosphere, as more and more fossil fuel is burned, will trap more and more heat from the sun at the surface of the Earth and so cause global temperatures to rise. Recent reports on the greenhouse effect have been issued by the Environmental Protection Agency, which held out little hope for avoiding its consequences, and the National Academy of Sciences, which, while predicting substantial effects, concluded that more study was needed before any action should be undertaken.

The new report done for the NSF says that, based on current understanding of the effect of carbon dioxide on climate and trends in global energy-use, 'a significant... warming in the next century probably cannot be avoided. ${ }^{*}$ However, the rate of increase of atmospheric

* See, for example, the paper on 'Energy and Climate', by Professor Roger R. Revelle \& Dr Donald C. Shapero, published in our Summer issue of 1978 (Environmental Conservation, 5(2), pp. 81-91).-Ed. 